\title{
Brazilian stock market bubble in the 2010s
}

\author{
Márcio P. Laurini ${ }^{1}$ (D) . Pedro Chaim ${ }^{2}$ (D)
}

Received: 3 May 2020 / Accepted: 23 September 2020 / Published online: 2 November 2020

(c) Springer Nature Switzerland AG 2020

\begin{abstract}
Brazilian stock markets underwent a period of remarkable exuberance between early 2016 and March 2020, only to crash with the global turmoil related to health worries and oil prices. The Ibovespa index tripled its market value between a low point in January 2016 and its maximum in January 2020 — by March 12, half those gains had been erased. Narratives about a bubble in Brazilian stocks before the global crash and its subsequent burst are plentiful in specialized media. In this paper, we explore this narrative from within the framework of strict local martingale financial bubbles. A key result in this literature states some financial asset price displays a bubble only if it follows a strict local martingale under the equivalent risk-neutral measure. A diffusion process is a strict local martingale if its volatility increases faster than linearly as its level grows. We first apply a nonparametric method to estimate the volatility function of Ibovespa daily prices, then fit a stochastic volatility model whose parameter values can discriminate the underlying price process as either a true martingale or a strict local martingale. Our results are negative towards the presence of a strict local martingale bubble in the Ibovespa index. Strict local martingale bubbles are related to a positive relationship between returns and volatility which does not seem present in the data at hand. We also performed a comparative analysis of the patterns found for the Ibovespa with the S\&P500 index, spot Brent oil and gold prices.
\end{abstract}

Keywords Financial bubble $\cdot$ Systemic crisis $\cdot$ Risk $\cdot$ Volatility

JEL Classification G95 $\cdot \mathrm{C} 11 \cdot \mathrm{G} 23$

Electronic supplementary material The online version of this article (https://doi.org/10.1007/s4354 6-020-00005-w) contains supplementary material, which is available to authorized users.

Márcio P. Laurini

laurini@ fearp.usp.br

1 Department of Economics, FEARP, University of São Paulo, Av. dos Bandeirantes 3900, Ribeirao Preto 14040-950, Brazil

2 Department of Economics, Federal University of Santa Catarina, Florianópolis, Brazil 


\section{Introduction}

Brazilian stock markets underwent a period of remarkable exuberance between early 2016 and March 2020, only to crash with the global turmoil related to COVID-19 pandemic and falling oil prices. The Ibovespa index tripled its market value between a low point in January 2016 and its maximum in January 2020by March 12, 2020, half those capital gains had been erased. Narratives about a bubble in Brazilian stocks before the global crash and its subsequent burst are plentiful in specialized media, e.g., Martins (2020), with the opinions of some of the biggest financial asset managers on a possible bubble on the Ibovespa.

In this paper, we employ statistical techniques to explore this narrative within the framework of strict local martingale (SLM) financial bubbles, developed for example by Jarrow et al. (2007), Jarrow et al. (2010) and Jarrow et al. (2011). The SLM approach differs from traditional bubble detecting exercises, in that it avoids the problematic double hypothesis of simultaneously testing a model of market equilibrium and investigating deviations from such equilibrium (what we tend to call bubbles). Camerer (1989) reviews this early literature and considers it inconclusive. Because future cash flows are not observable, pinpointing some financial asset's fundamental value is not straightforward; and thus, observed deviations from expected behavior can come either from the real presence of a price bubble or from model misspecification. The issue here is that the model can not be independently validated. For examples of this literature, see Flood and Hodrick (1986), Smith et al. (1988), Camerer and Weigelt (1991), and also Nunes and Silva (2009) for an application to Brazilian markets.

Specifically, the SLM approach circumvents the joint hypothesis hindrance by focusing on purely statistical properties of prices and returns. A key result in this literature states some financial asset price displays a bubble only if it follows a strict local martingale under the equivalent risk-neutral measure. A diffusion process is a strict local martingale if its volatility increases faster than linearly as its level grows. The condition given by Eq. (4), described in "Financial bubbles and strict local martingales", provides a testable implication of the SLM hypothesis through the estimation of the variance function of the price process. If variance increases faster than linearly with level, then the integral in Eq. (4) is finite and characterizes a strict local martingale. Another approach involves estimating a stochastic volatility model similar to the one studied by Andersen and Piterbarg (2007), whose parameter value configuration characterizes the underlying process as either a true martingale or a strict local martingale. For exercises of bubble detection within this framework see, for example, Obayashi et al. (2017), Baldeaux et al. (2018), Chaim and Laurini (2019), Cretarola and Figà-Talamanca (2019).

Thus, in this paper, we investigate the presence of price bubble in the Ibovespa index using the SLM framework and techniques just mentioned. Because Ibovespa is a value-based index of stocks which is often pointed to as a diversified portfolio of Brazilian stocks, the presence of a bubble in such index raises issues in risk management and portfolio allocation with Brazilian stocks. We employ a 
nonparametric method proposed by Florens-Zmirou (1993) to estimate Ibovespa's price-variance function, and then, we use a posterior simulation algorithm for Bayesian estimation of the stochastic volatility model (5). Based on a test for structural change in the mean of Ibovespa returns, we split our sample in two subsamples and conduct those analysis accordingly. The first subsample ranges from January 4th, 2010, until January 26th, 2016; and the second subsample goes from January 27th, 2016, until the end of our sample on March, 12th, 2020.

Results are overall negative towards the presence of a price bubble in Ibovespa during the analyzed period and subdivisions. Estimated variance functions plotted in Figs. 2 and 3 do not suggest variance increases for higher observed prices, thus not characterizing SLM behavior according to the condition in Eq. (4). Posterior estimates of the stochastic volatility model of Andersen and Piterbarg (2007) do not fall within the SLM range established on the criteria from Theorem 1-specifically, there is comparatively little probability attributed to a positive correlation coefficient between random shocks to returns and volatility, which is a necessary condition for SLM dynamics.

Financial connectedness measures, as for example based on Diebold and Yilmaz (2009), suggest the Ibovespa index has a relevant connection with global markets, with the relative impact of international shocks amplified with the tumultuous developments of $2020^{1}$. To provide some international comparison and context, we also conduct our analysis for three assets of great global importance: the S\&P500 index, spot Brent oil prices, and spot gold prices. Figure 4 plots estimated variance functions and Table 7 reports posterior distributions of the stochastic volatility model (5). Results for S\&P500 and oil prices are qualitatively similar to those obtained for the Ibovespa index. Specifically, nonparametric estimates of their variance functions do not increase faster than linearly as price grows, as required by the SLM condition in Eq. (4); furthermore, in our estimations of the stochastic volatility model (5), there is no evidence of a positive correlation coefficient between random shocks to returns and volatility. Gold prices seem to be an exception. Interestingly, gold price dynamics seem different from what was observed for the other assets. Nonparametric estimation of its variance function suggests a sharp increase for higher observed prices and convergence of the integral in Eq. (4), characteristic of a strict local martingale process. Also, parametric estimation of the stochastic volatility model (5) attributes high probability to a positive correlation between shocks to Gold returns and unobserved volatility, thus characterizing the underlying price process as a strict local martingale according to the criteria in Theorem 1.

We take the results presented here as indication that the high returns experienced by Brazilian stocks from 2016 onward and the sudden drop in prices in March 2020, are not the case of a bubble forming up and then bursting — but better explained by market fundamentals and international spillovers. Qualitatively similar dynamics are observed for Ibovespa, S\&P500, and oil. Namely, the absence of a positive price-variance feedback relationship, that is characteristic of strict local martingale

\footnotetext{
1 Specifically, we point to the "To Connectedness" measure of stock market volatility which can be consulted in the website http://financialconnectedness.org/.
} 
bubbles, which reinforces the notion of those assets having typical behavior during the analyzed period.

The remainder of this paper is organized as follows. "Financial bubbles and strict local martingales" states some key concepts and definitions underpinning our exercises. "Data description and context" describes the data and touches some important Brazilian economic and political developments during the period. "Results" presents and discusses our results. "Conclusion" provides some concluding remarks.

\section{Financial bubbles and strict local martingales}

The first theorem of asset pricing states there exists a risk-neutral probability measure $Q$, equivalent to the physical measure $P$, such that some asset's discounted price $S / B$ follows a local martingale under $Q$. A local martingale can either be a "true" martingale, whose best guess for future values is the current value of the process, or a strict local martingale. A strict local martingale is not a "true" martingale, but a supermartingale because its expected value decreases with time. Jarrow et al. (2007), Jarrow et al. (2010) and Jarrow et al. (2011), among others, develop a theory that links the existence of a (positive) bubble in some asset's price to strict local martingale behavior under the equivalent measure.

Now, we repeat some important definitions. More specifically, following Protter (2013), consider an economy in which are traded a risky asset and a money market account in the time interval $[0, T]$. For simplicity, assume there are no cash flows associated with the asset. Consider a complete probability space $\left(\Omega, \mathcal{F}_{t}, P\right)$ with filtration $\mathbb{F}=\left(\mathcal{F}_{t}\right)_{t \geq 0}$. Let $r=\left(r_{t}\right)_{t \geq 0}$ represent the instantaneous default-free spot interest rate, then the value of the money market account at time $t$ is given by:

$$
B_{t}=\exp \left(\int_{0}^{t} r_{u} d u\right) .
$$

The first theorem of asset pricing (Delbaen and Schachermayer 1998) states no arbitrage in the sense of no free lunch with vanishing risk implies that there exists a probability measure $Q$, equivalent to the physical measure $P$, such that some asset's discounted price:

$$
\bar{S}_{t}=\frac{S_{t}}{B_{t}},
$$

is a local martingale under $Q$. A local martingale is an adapted càdlàg stochastic process $M_{t}$, for which there exists an increasing sequence of stopping times $\left(\tau_{n}\right)_{n \geq 0}$ such that $\mathrm{t} \lim _{n \rightarrow \infty} \tau_{n}=\infty$, and $M_{\min \left\{t, \tau_{n}\right\}}$ is a martingale with probability one for all $n$.

Let $S_{T}$ be the liquidation value of the asset at time $T$. Protter (2013) defines the fundamental price of the asset $S_{t}^{\star}$, which pays no dividends, as the expectation of the liquidation value $S_{T}$ under the equivalent local measure $Q$, it is the value of holding the value until time $T$, 


$$
S_{t}^{\star}=E_{Q}\left(\frac{S_{T}}{B_{T}} \mathbf{1}_{\{t \leq T\}} \mid \mathcal{F}_{t}\right) B_{t} .
$$

The asset price bubble $\beta_{t}$ is defined as the difference between the observed market price $S_{t}$ and the fundamental asset value $S_{t}^{\star}$, assumed nonnegative,

$$
\beta_{t}=S_{t}-S_{t}^{\star} .
$$

Protter (2013) shows that saying some finitely lived risky asset $S_{t}$ has nonzero bubble $\beta_{t}$ on $[0, T]$ is equivalent to saying $S_{t}$ is a strict local martingale under the equivalent risk-neutral measure $Q$.

We now assume the risky asset price $S=\left(S_{t}\right)_{t \geq 0}$ is driven by a standard stochastic differential equation:

$$
d S_{t}=\mu\left(S_{t}\right) d t+\sigma\left(S_{t}\right) d W_{t}^{S} .
$$

NFLVR implies there exists an equivalent local martingale measure under which this SDE simplifies to,

$$
\frac{S_{t}}{B_{t}}=S_{0}+\int_{0}^{t} \sigma\left(S_{s}\right) d W s .
$$

As shown by Kotani (2006) and Mijatović and Urusov (2012), the process $\bar{S}=(S / B)$ is a strict local martingale if and only if

$$
\int_{\epsilon}^{\infty} \frac{x}{\sigma(x)^{2}} d x<\infty,
$$

for some $\epsilon>0$. The fitness of the integral in expression (4) can be empirically tested, for example, using nonparametric estimator based on Florens-Zmirou (1993) and Jiang and Knight (1997).

In the empirical literature, sometimes, the raw observed price $S_{t}$ is considered in the estimations. This is at times justified on the grounds that the time interval under analysis is small or that it is not clear which interest rate remunerates the money market account. In this paper, we decided to perform the procedures for both raw observed Ibovespa prices $S$ and discounted prices $\bar{S}=(S / B)$, constructed by compounding Ibovespa daily excess returns with respect to the interbank rate (in Portuguese Certificado de Depósito Interbancário — CDI, Interbank Deposit Certificate), details below. Our results are qualitatively invariant to this specification choice.

Now imposing some more structure, suppose the dynamics of $S$ follow the stochastic volatility model:

$$
\begin{aligned}
& d S_{t}=\lambda S_{t} \sqrt{V_{t}} d W_{t}^{S}, \\
& d V_{t}=\kappa\left(\theta-V_{t}\right)+\epsilon V_{t}^{p}, d W_{t}^{V}
\end{aligned}
$$

where $\lambda, \kappa, \theta, p>0$, and $\left(W_{t}^{S}, W_{t}^{V}\right)$ is a two-dimensional Brownian motion with correlation coefficient $\rho$. 
Results of Andersen and Piterbarg (2007) and Protter (2013) describe how the parameter space of model (5) can be divided into two disjoint sets, such that a specific parameter range characterizes $S$ as a strict local martingale, thus allowing for a testable implication of the martingale hypothesis. Specifically, the result bellow is Theorem 7 of Protter (2013).

Theorem 1 For model (5): if $\rho \leq 0, S$ is a true martingale; if $\rho>0$ and $p \leq 1 / 2$ or $p>3 / 2, S$ is a true martingale; if $\rho>0$ and $1 / 2<p<3 / 2$, then $S$ is a strict local martingale. For the case $p=3 / 2, S$ is a true martingale if $\rho \leq 1 / 2 \epsilon \lambda^{-1}$, and $S$ is a strict local martingale if $\rho>\epsilon \lambda^{-1} / 2$.

Proof See Proposition 2.5 of Andersen and Piterbarg (2007).

Baldeaux et al. (2018) investigate the presence of bubbles in money markets by estimating models similar to (5), and comparing estimated parameter values to the conditions in Theorem 1. They find that the fitted models can produce bubbles. Scale parameter $\lambda$ has been proven specially hard to identify in empirical exercises. Here, we follow the solution of Baldeaux et al. (2018) which is to calibrate its value to one.

\section{Data description and context}

We consider daily closing prices of the Ibovespa index between January 4th, 2010 and March 12th, 2020. As default-free interest rate, we employ the daily $\mathrm{CDI}^{2}$ rate. We compute the discounted price $\bar{S}=(S / B)$ by setting the portfolio value at our first date to 100 , then capitalizing daily excess returns of Ibovespa with respect to CDI.

$$
\bar{S}_{t}=\bar{S}_{t-1} \exp \left(\log \left(\frac{S_{t}}{S_{t-1}}\right)-r_{t}\right),
$$

with $S_{0}=100$. Here, $r_{t}$ is the annualized CDI rate, transformed in daily terms using 252 workdays in a year.

Figure 1 plots the trajectories of Ibovespa prices $S$ on top panel (a), the CDI accumulated gains $B$ and instantaneous rate $r$ [mid panel (b)], and the discounted price $(S / B)$ computed as described before [bottom panel (c)].

Naive visual inspection of Ibovespa's price trajectories in Fig. 1 suggests some change in its dynamics from early 2016 onwards when compared to its previous period. For example, on January 26th, 2016, the Ibovespa index attained its minimum value for the decade, and then experienced a rapid valuation through the next four years until March 2020.

\footnotetext{
${ }^{2}$ The Certificado de Depósito Interbancário (CDI) - Interbank Deposit Certificate is the main reference for risk free rate for the financial market in Brazil. It is an average of the daily fees charged in the interbank loan market.
} 

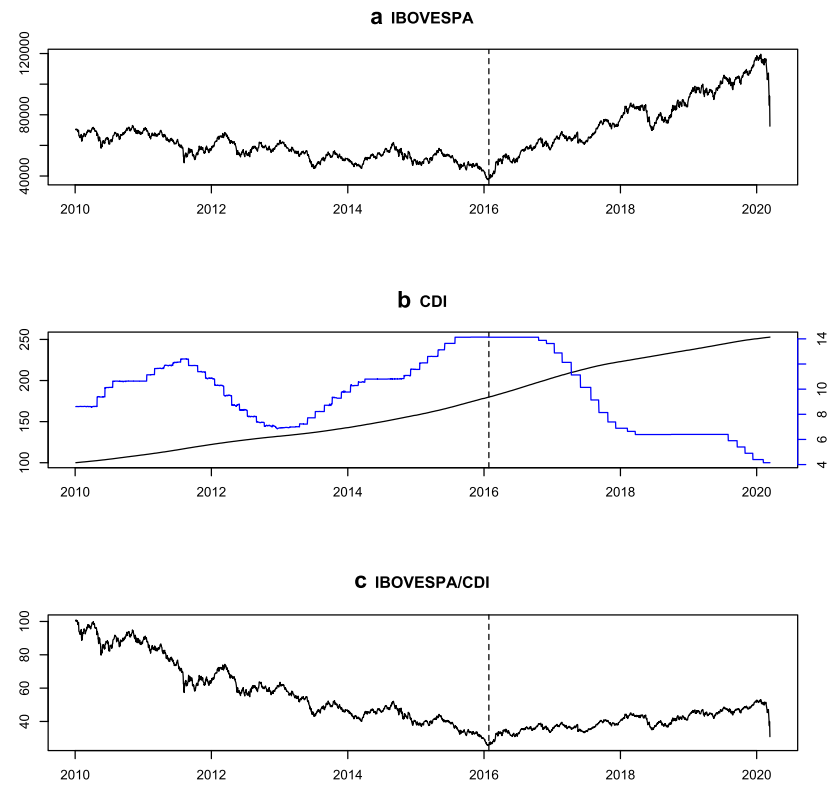

Fig. 1 The figure shows a evolution of the closing value of the Ibovespa, $\mathbf{b}$ the CDI rate and the accumulated value of the rate, with the left axis being the accumulated value and the right axis being the value of the CDI rate, and $\mathbf{c}$ the Ibovespa excess return in relation to the CDI, on a basis starting at 100. Vertical dashed lines show the subsample split

We test for structural breakpoints in the mean of Ibovespa returns using a dynamic programming method based on Bai and Perron (1998), Bai and Perron (2003), and Zeileis et al. (2003), which choses break dates by minimizing the Bayesian Information Criterion within a minimal sample length segment. Table 1 summarizes the results for one up to five mean returns structural breakpoints. The date January 26th, 2016, is chosen by the algorithm as the single breakpoint, as well as featuring when two, three and four breaks are considered. We thus chose to split our sample in two, using January 26th, 2016, as the split date. January 4th, 2010 until early 2016 represents the overall bearish environment of Brazilian stock markets during the period; while the second subsample which ranges from January 27th, 2016, until March 12th, 2020, captures the period of rapid capital gains of Brazilian stocks, up until the "coronacrash" episode of March 2020.

Table 2 reports descriptive statistics of Ibovespa prices and returns for the three subsamples described above. We fist notice the first subsample has a negative mean return of -0.0401 , while the second subsample has positive mean returns of 0.0625 ; this is due to our choices when splitting the sample. All subsamples of returns display negative skewness coefficient, but the magnitude is larger for the latter subsample. Due to more extreme daily returns, excess kurtosis is larger for the latter subsample.

We now superficially review some important economic and political developments in Brazil during the decade of 2010 as to provide some illustration of the environment in which a supposed stock price bubble would have built up. Some 
Table 1 Results from structural breakpoints tests of Ibovespa mean daily returns

\begin{tabular}{|c|c|c|c|c|}
\hline Number of & Returns mean breakpoints dates & servation num & & \\
\hline 1 & & & $\begin{array}{l}2016-01-26 \\
(1499)\end{array}$ & \\
\hline 2 & & & $\begin{array}{l}\text { 2016-01-26 } \\
(1499)\end{array}$ & $\begin{array}{l}2018-02-23 \\
(2015)\end{array}$ \\
\hline 3 & & $\begin{array}{l}2014-07-14 \\
(1120)\end{array}$ & $\begin{array}{l}2016-01-26 \\
(1499)\end{array}$ & $\begin{array}{l}2018-02-23 \\
(2015)\end{array}$ \\
\hline 4 & 2011-08-05 (396) & $\begin{array}{l}2014-07-14 \\
(1120)\end{array}$ & $\begin{array}{l}2016-01-26 \\
(1499)\end{array}$ & $\begin{array}{l}2018-02-23 \\
(2015)\end{array}$ \\
\hline 5 & $\begin{array}{cc}2011-07-12(378) & (756)\end{array}$ & $\begin{array}{l}\text { 2014-08-01 } \\
(1134)\end{array}$ & $\begin{array}{l}2016-02-15 \\
(1512)\end{array}$ & $\begin{array}{l}2018-02-23 \\
(2015)\end{array}$ \\
\hline
\end{tabular}

The procedure is based on Zeileis et al. (2003)

aggregate statistics are presented in Table 3 to help the reader to follow the narrative below.

The first year in our sample, 2010, corresponds to the end of Luiz Inácio Lula da Silva (Worker's Party, PT) two four-year presidency terms. Much due to the high popularity of her predecessor, Dilma Rousseff (PT), Lula's appointed successor, was elected president in the 2010 general elections. Brazil was less adversely affected by the global financial crisis than the majority of developed countries. After only a mild contraction of $-0.13 \%$ in 2009 , real GDP grew by $7.53 \%$ in 2010 . From the turn of the century up until the last years of Lula's presidency, Brazilian macroeconomic policy doctrine was to pursue a so called "Macroeconomic Tripod" (in Portuguese, Tripé Macroeconômico) characterized by the precepts of floating exchange rate, inflation targeting monetary policy, and sustained fiscal surpluses. In hopes of maintaining the rapid GDP growth of previous years, the ruling Worker's Party gradually shifted to a more expansionist and interventionist stance, foregoing much of the austerity implied by the previous paradigm. The break is explicit when in July 2012 the finance Minister Guido Mantega said in interview the Government was now following a "New Economic Matrix" (in Portuguese, Nova Matriz Econômica). The New Economic Matrix is more difficult to precisely define, and as term is more commonly used to refer to policies implemented roughly between 2011 and 2014; for example reducing energy prices, increasing credit supply by state-owned banks, and ambitious plans for infrastructure projects. The policy that is most salient from the perspective of our study here is the interest rates cuts which happened between 2011 and 2013. Those cuts were largely perceived as executive interference over Central Bank affairs. It can be said such measures were not effective in practice as GDP growth slowed in 2014 and the country plunged into deep recession in 2015 and 2016. Consumer price inflation pressure steadily built up over those years, running above the Central Bank's official target of $3.5 \%$.

In 2016, Dilma was impeached in favor of her vice president Michael Temer (Brazilian Democratic Movement, MDB) under charges of fiscal fraud. Although the entire process stretched from December 2015 to August 2016, on May 12th, 2016, 


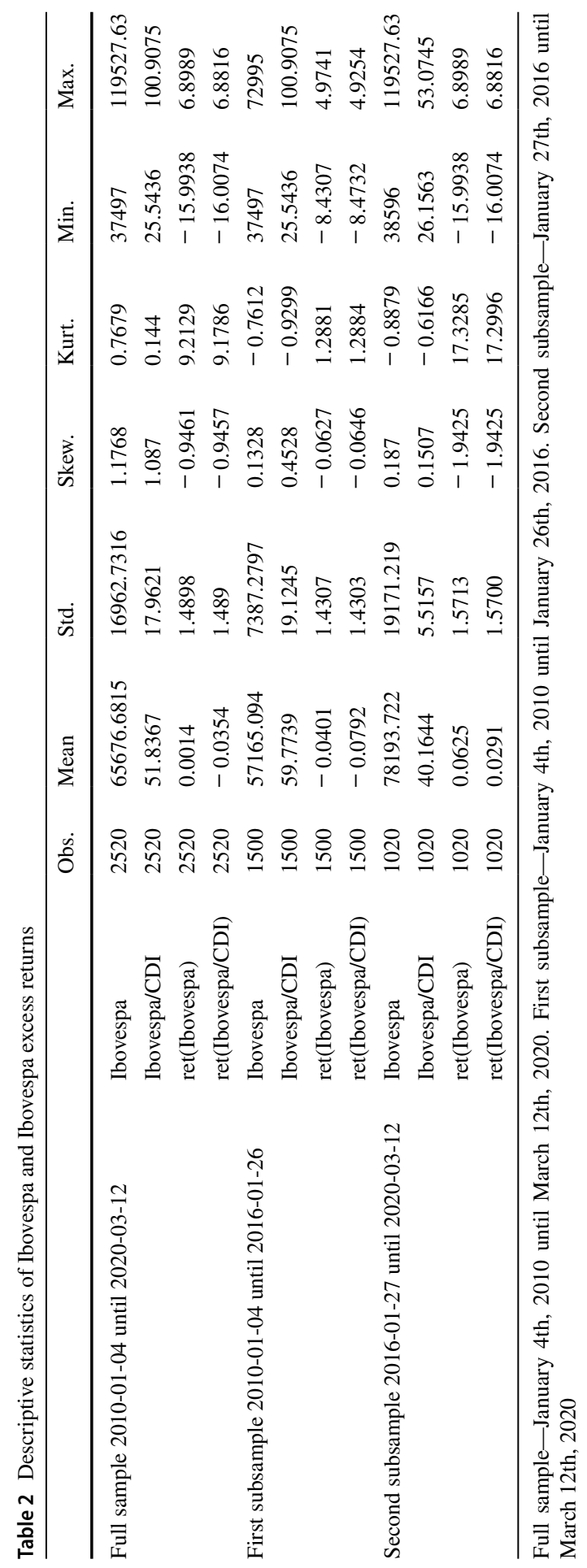


Table 3 Aggregate yearly Brazilian figures on consumer price inflation, real gross domestic product growth, and government debt as portion of gross domestic product

\begin{tabular}{llllllll}
\hline Year & $\begin{array}{l}\text { CPI inflation } \\
(\%)\end{array}$ & $\begin{array}{l}\text { Real GDP } \\
\text { growth } \\
(\%)\end{array}$ & Debt/GDP $(\%)$ & Year & $\begin{array}{l}\text { CPI inflation } \\
(\%)\end{array}$ & $\begin{array}{l}\text { Real GDP } \\
\text { growth } \\
(\%)\end{array}$ & Debt/GDP (\%) \\
\hline 2009 & 4.31 & -0.13 & 59.21 & 2015 & 10.67 & -3.55 & 65.50 \\
2010 & 5.91 & 7.53 & 51.77 & 2016 & 6.29 & -3.28 & 69.84 \\
2011 & 6.50 & 3.97 & 51.27 & 2017 & 2.95 & 1.32 & 73.74 \\
2012 & 5.84 & 1.92 & 53.67 & 2018 & 3.75 & 1.32 & 76.53 \\
2013 & 5.91 & 3.00 & 51.54 & 2019 & 4.31 & 1.14 & 75.79 \\
2014 & 6.41 & 0.50 & 56.28 & & & & \\
\hline
\end{tabular}

Temer became acting president. Temer's macroeconomic policy agenda focused on consolidating governmental finances and were perceived very favorably by financial markets. A law dubbed "Spending Ceiling" (in Portuguese, Teto de Gastos) was passed in December 2016. It provided targets and guidelines for reducing government debt over subsequent years. Favorable expectations regarding future dynamics of Brazilian government debt are largely pointed at as a major driver for the steadily lowering interest rates ever since mid 2016. In the general elections of 2018, Jair Bolsonaro (Liberal Social Party, PSL) was elected president. Although the political environment has been tumultuous ever since before his stepping into office, Bolsonaro's macroeconomic policy has been broadly perceived as continuation of previous years. Notably, 2019 was dominated by efforts to pass through congress a long overdue constitutional amendment regulating broad changes in the state pension system. The COVID-19 pandemic has spurred a surge in government spending under emergence character. Fiscal targets established by the Spending Ceiling law will not be attained. It is not yet clear how this will affect market macroeconomic variables.

We conduct our analysis in parallel for three other financial assets of greater global economic importance: the S\&P500 index, Brent spot oil prices, and spot gold prices. Our hopes are to provide some international context for comparison against the Brazilian stock market experience during the analyzed period.

The S\&P500 represents a diversified portfolio of mature stocks, whose behavior expresses "standard" stock price dynamics. Some stocks with considerable weight in the composition of the Ibovespa index have their performance related to energy prices, specially crude oil (the preeminent example being the partially state-owned Petrobras). The price of oil also fell sharply in early 2020, displaying similar dynamics to those from the Ibovespa index that help motivate our exercise. Gold is broadly seen as a "safe haven" asset used as hedge against fluctuation in capital markets and interest rate variations. Gold also does not have as explicit commodity value as shares of ownership in companies or fossil fuel. Descriptive statistics of those assets' prices and returns are reported in Table 4.

Further details on data sources presented in Appendix 2 (Supplementary material). 
Table 4 Descriptive statistics of the S\&P500 index, brent crude oil prices, and gold prices

\begin{tabular}{llllllll}
\hline & Obs. & Mean & Std. & Skew. & Kurt. & Min. & Max. \\
\hline SP500 & 2564 & 1986.725585 & 608.1328664 & 0.2372123 & -1.0374157 & 1022.58 & 3386.15 \\
Ret (SP500) & 2564 & 0.03056382 & 0.9907686 & -1.0219205 & 9.6268604 & -9.994485 & 4.840324 \\
Oil & 2580 & 78.90719767 & 26.0574457 & 0.1285603 & -1.3604708 & 26.01 & 128.14 \\
Ret (oil) & 2580 & -0.03625769 & 2.004182 & -0.7498313 & 12.6326268 & -25.517526 & 11.070133 \\
Gold & 2655 & 1366.493258 & 193.2936689 & 0.820936 & -0.2743677 & 1049.4 & 2067.15 \\
Ret (gold) & 2655 & 0.02237044 & 1.0053535 & -0.4891968 & 6.4649077 & -9.596165 & 5.133427 \\
\hline
\end{tabular}

Sample from January 4th, 2010 until March 12th, 2020. Data was collected from FRED, Federal Reserve Bank of St. Louis, website

\section{Results}

\section{Volatility function}

In this section, we report the results of the non-parametric estimation of the strict local martingale condition, given by the integral in Eq. (4). We estimate the volatility function $\sigma^{2}(\cdot)$ using the nonparametric estimator of variance functions FlorensZmirou (1993) and Jiang and Knight (1997).

Assuming an continuous stochastic process $S=\left(S_{t}\right)_{0 \leq t \leq T}$, and $\left\{S_{t}=S_{t_{1}}, S_{t_{2}}, \ldots, S_{t_{n}}\right\}$ a sequence of $n$ equispaced observations of process $S$ at times $\left\{t_{1}=\Delta_{n}, t_{2}=2 \Delta_{n}, \ldots, t_{n}=n \Delta_{n}\right\}$, with $\Delta_{n}=T / n$. The nonparametric estimator of variance function using the observed sampling path of the diffusion process $S_{t}$ at points $x$ is:

$$
\hat{\sigma}^{2}(x)=\frac{\sum_{i=1}^{n-1} n K\left(\frac{S_{i \Delta_{n}}-x}{h_{n}}\right)\left[S_{(1+i) \Delta_{n}}-S_{i \Delta_{n}}\right]^{2}}{\sum_{i=1}^{n} T K\left(\frac{S_{i \Delta_{n}}-x}{h_{n}}\right)},
$$

with $h_{n}>0$ a bandwidth parameter, and $K(\cdot)$ is a kernel function. We employ a Gaussian kernel, and set the bandwidth parameter specified by Kullback-Leibler cross-validation ( Hurvich et al. 1998).

Figure 2 presents nonparametric estimates of Ibovespa observed price $S$ variance functions $\hat{\sigma}\left(S_{t}\right)$ for our three subsamples. Plots in the left column display, for each subsample, the estimates of diffusion coefficients $\hat{\sigma}(\cdot)$ as function of prices $S_{t}$, shaded areas represent $95 \%$ confidence bands; while plots in the right column display the ratio $S_{t} / \hat{\sigma}\left(S_{t}\right)$, integrand in Eq. (4). Remember $S$ is a strict local martingale if the integral in condition Eq. (4), represented by the area bellow the graphs in the right column, is finite. We notice that for all subsamples considered, variance $\hat{\sigma}^{2}(\cdot)$ is either decreasing or stable for higher values of $S$, indicating condition (4) is not satisfied.

Figure 3 plots the nonparametric estimates for Ibovespa prices taken in terms of the accumulated gains over CDI. From variance function estimates in left column 
a Full Sample: 2010-03-04 to 2020-03-12
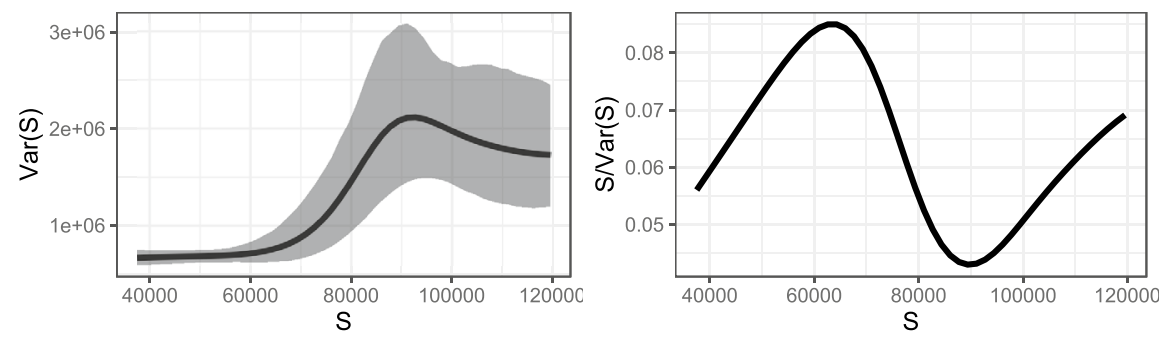

b 1st subsample: 2010-03-04 to 2016-01-26
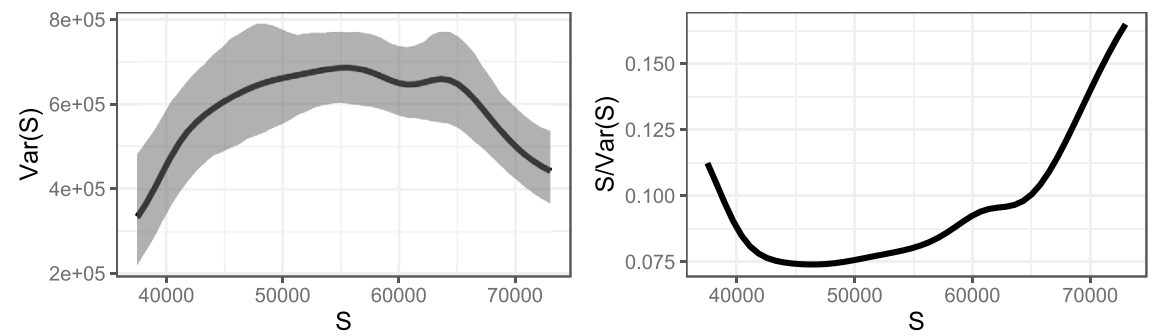

C 2nd subsample: $2016-01-27$ to $2020-03-12$
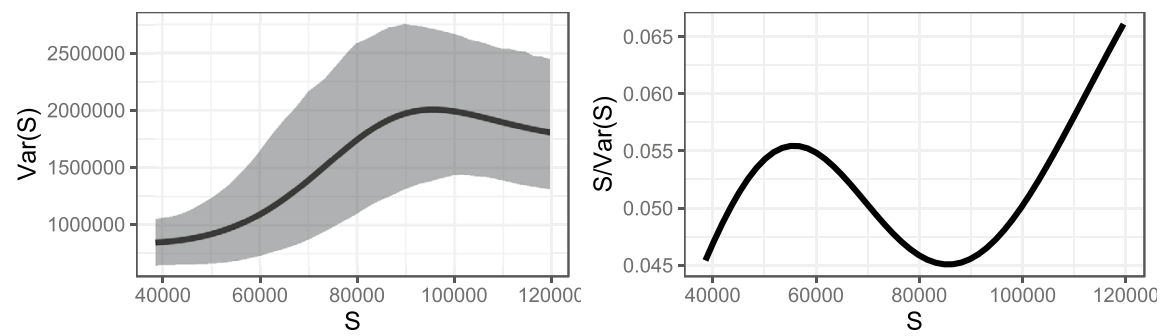

Fig. 2 Nonparametric estimation of variance functions and SLM conditions-raw Ibovespa prices

plots, we see price variability does not increases faster than linearly as price level grows. Plots in the right column give no indication the SLM condition is satisfied.

Thus, our nonparametric evidence is negative towards the presence of a bubble in Ibovespa prices for all sampling periods, and this evidence is not affected by specifying observed or discounted prices. We observe the more typical behavior of variance remaining stable or dropping the higher the price level attained by the asset.

Figure 4 plots the results of nonparametric estimation of the variance function of prices of the three international assets included in our analysis. There is no indication of explosive level-variance relationship when we apply the nonparametric estimation method on S\&P500 and oil prices, much in line with the results for Ibovespa. We observe variance stable or diminishing with higher price levels, as characteristic of non bubble dynamics. Interestingly, Gold prices seem to be an exception. From panel (c) we can see that although confidence bands are broad, there is indication of its variance increasing faster than linearly with level, as can be noted from a sharp drop in the level-variance ratio from the right plot of panel (c). 
a Full Sample: $2010-03-04$ to $2020-03-12$
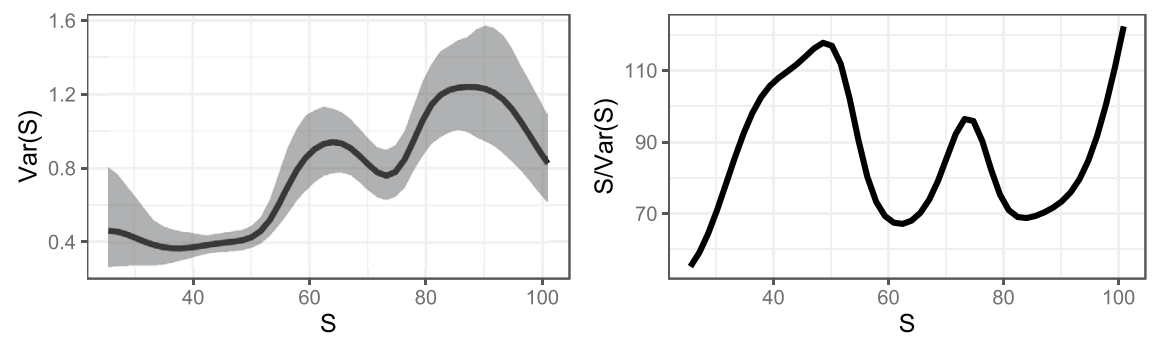

b 1st subsample: $2010-03-04$ to $2016-01-26$
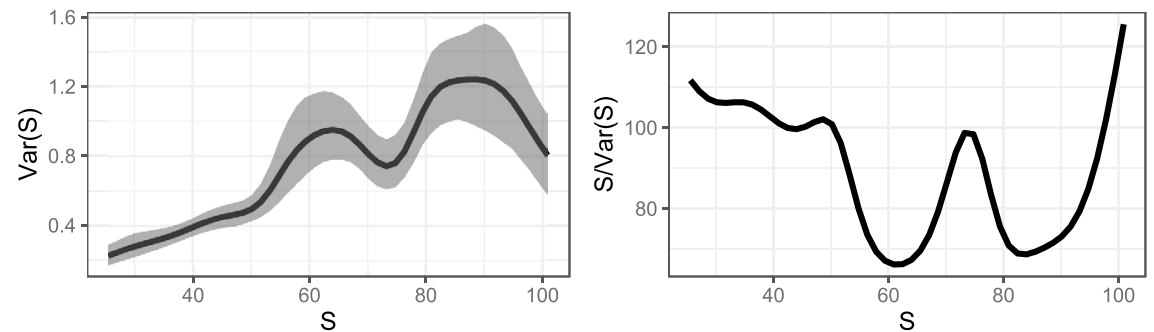

C 2nd subsample: $2016-01-27$ to $2020-03-12$
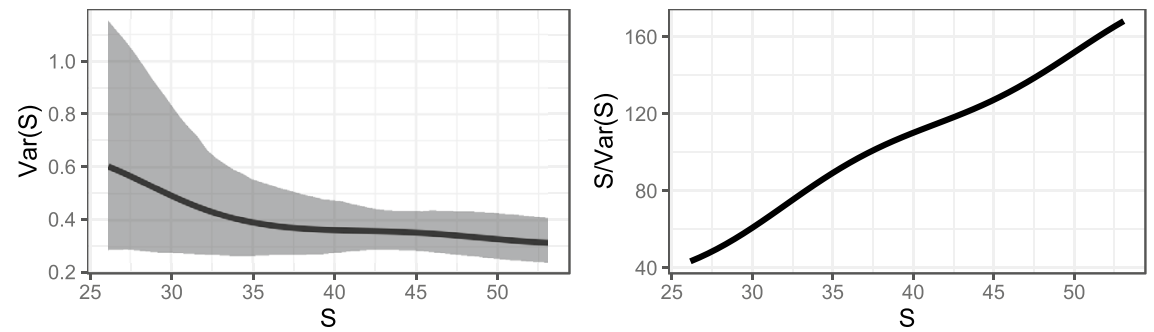

Fig. 3 Nonparametric estimation of variance functions and SLM conditions-discounted Ibovespa prices

\section{Stochastic volatility model}

Now, we turn to the parametric approach of fitting a stochastic volatility model based on Andersen and Piterbarg (2007). Recall from our brief discussion that depending on the configuration of parameter values, the underlying diffusion process is either a true martingale or a strict local martingale. Repeating here model (5) we have,

$$
\begin{aligned}
d S_{t} & =\lambda S_{t} \sqrt{V_{t}} d W_{t}^{S}, \\
d V_{t} & =\kappa\left(\theta-V_{t}\right)+\epsilon V_{t}^{p} d W_{t}^{V},
\end{aligned}
$$

with $\rho$ as correlation parameter between Brownian motion $\left(W^{S}, W^{V}\right)$. Again, we estimate the model for both observed Ibovespa prices $S$ and its price discounted with accumulated CDI gains, $\bar{S}=S / B$. 
a S\&P500
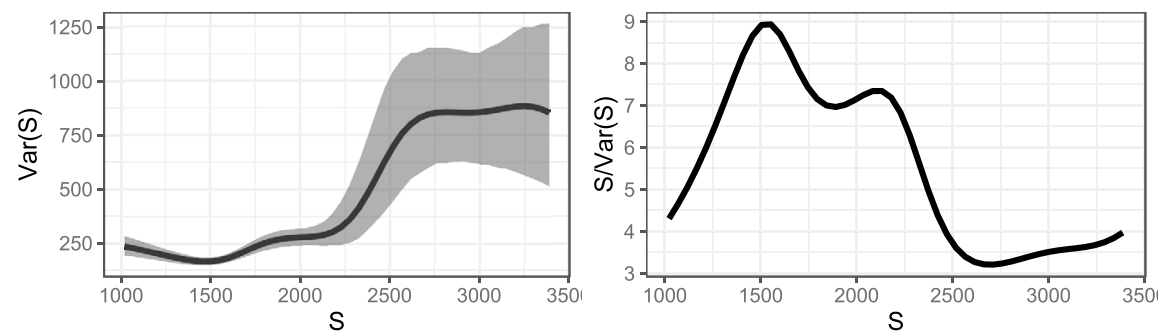

b OIL
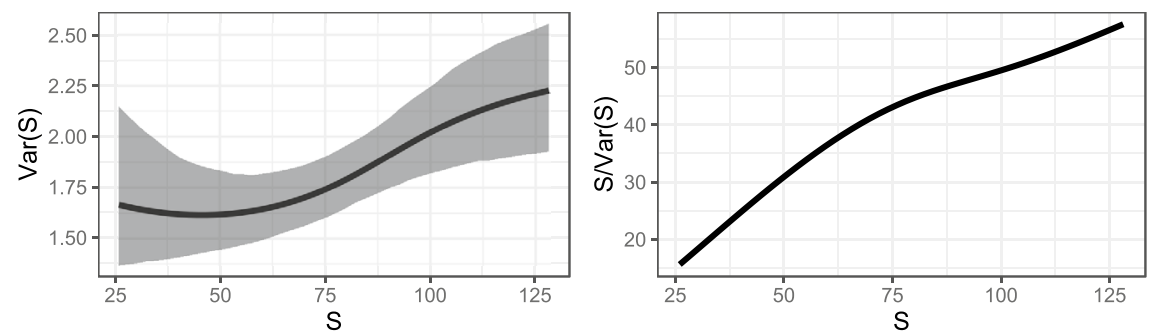

c GOLD
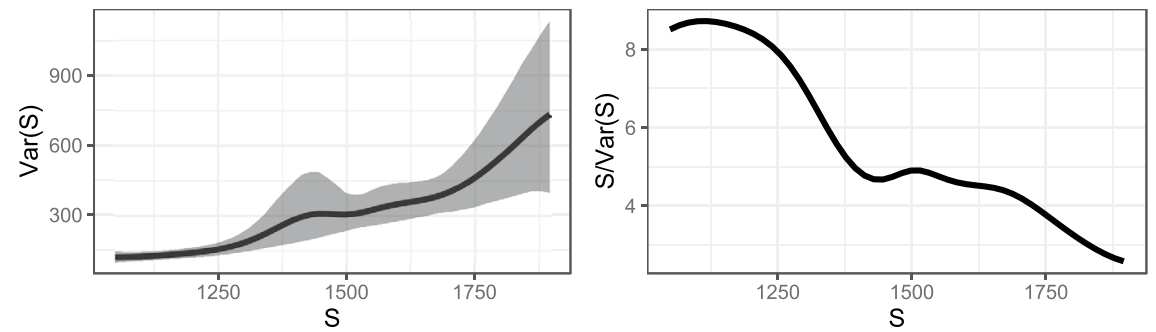

Fig. 4 Nonparametric estimation of variance functions and SLM conditions-S\&P500, oil, and gold prices

From Theorem 7 of Protter (2013), we see that for the underlying process to follow strict local martingale, we need parameter $p$ between 0.5 and 1.5 and that the correlation between shocks to returns and volatility $\rho$ to be positive.

Due to the latent nature of volatility $V_{t}$, we estimate the model using some Bayesian posterior simulation method, as is usual in the literature. Specifically, we employ the NUTS Hamiltonian Monte Carlo method, introduced by Duane et al. (1987). Posterior values are drawn from a chain of 100,000 iterations. More details in Appendix 1 (Supplementary material).

Table 5 reports results when estimating the model with observed raw Ibovespa returns, and Table 6 reports posterior descriptive statistics of model (5) parameters estimates using Ibovespa excess returns relative to the daily CDI rate. Parameter estimates are relatively stable through both sample and asset specifications, and yield the same qualitative conclusion when observing the requirements of Theorem 1. 
Table 5 Posterior distributions, stochastic volatility model-Ibovespa

\begin{tabular}{|c|c|c|c|c|c|c|}
\hline Ibovespa & & Mean & Std. & $\mathrm{q} 2.5 \%$ & Median & $\mathrm{q} 97.5 \%$ \\
\hline \multirow[t]{5}{*}{ Full sample } & $\kappa$ & 0.6513 & 0.2062 & 0.2164 & 0.6702 & 0.9746 \\
\hline & $\theta$ & 0.0129 & 0.0041 & 0.0015 & 0.0142 & 0.0174 \\
\hline & $\epsilon$ & 9.6884 & 1.4157 & 7.0756 & 9.6481 & 12.6756 \\
\hline & $\rho$ & -0.2721 & 0.1761 & -0.5472 & -0.3038 & 0.0956 \\
\hline & $\mathrm{p}$ & 0.9162 & 0.0358 & 0.8466 & 0.9161 & 0.9858 \\
\hline \multirow[t]{5}{*}{ First subsample } & $\kappa$ & 0.6094 & 0.2114 & 0.1707 & 0.6243 & 0.9627 \\
\hline & $\theta$ & 0.0101 & 0.0051 & 0.0013 & 0.0104 & 0.0177 \\
\hline & $\epsilon$ & 7.3007 & 1.3472 & 4.8145 & 7.2452 & 10.1304 \\
\hline & $\rho$ & -0.0239 & 0.1124 & -0.2838 & -0.0103 & 0.1857 \\
\hline & $\mathrm{p}$ & 0.9395 & 0.0408 & 0.8589 & 0.9395 & 1.0184 \\
\hline \multirow[t]{5}{*}{ Second subsample } & $\kappa$ & 0.5325 & 0.2279 & 0.0819 & 0.5394 & 0.9416 \\
\hline & $\theta$ & 0.0136 & 0.0081 & 0.0007 & 0.0146 & 0.0263 \\
\hline & $\epsilon$ & 10.2464 & 1.4892 & 7.4981 & 10.1888 & 13.3311 \\
\hline & $\rho$ & -0.1911 & 0.2164 & -0.5847 & -0.2099 & 0.2148 \\
\hline & $\mathrm{p}$ & 0.8854 & 0.0369 & 0.8121 & 0.8857 & 0.9563 \\
\hline
\end{tabular}

Parameter $p$ gives the relative effect of random shocks to the unobserved volatility level $V_{t}$. Estimates of parameter $p$ fall wholly within the range $(0.5,1.5)$. This is a necessary condition for SLM behavior according to criteria of Theorem 1. Indeed, our estimations for all considered assets and subsamples yield such result.

A second requirement for some processes to follow a strict local martingale is positive correlation between shocks to volatility and returns. Estimated posterior distributions of $\rho$ in Tables 5 and 6 are quite disperse, with zero contained in all 95\% credibility intervals, but considerable more probability is attributed to negative values of correlation $\rho$. Thus, we do not observe Ibovespa returns-volatility dynamics displaying the "inverted leverage effect" which is required in order for $S$ to follow a strict local martingale process.

Days of large negative returns in the last days of the sample can be contaminated by the Circuit Break mechanism. The main episodes of Ibovespa circuit breaks in our sample happened during the recent coronacrash of March 2020. In 2020, the circuit breaker was triggered on March 9,11, 12 and 16, with the first three dates being part of our sample. This was the first time the mechanism was activated since March, 18, 2017, with affairs related to corruption investigations in Brazil. Theoretical motivations discussed in Greenwald and Stein (1991) and Kodres and O'Brien (1994) support a possible reduction in market volatility due to the activation of the circuit breaker. However, Kuhn et al. (1991) when analyzing cash and futures markets on October 13, 1989, find no evidence for the reduction of volatility due to the triggering of the circuit breaker. Other empirical studies, such as Santoni and Liu (1993), also do not find evidence of changes in volatility due to the use of these mechanisms.

Results from estimations of stochastic volatility model (5) for the three international assets considered are summarized in Table 7. As briefly alluded to before, 
Table 6 Posterior distributions, stochastic volatility model-Ibovespa excess returns

\begin{tabular}{lllllll}
\hline Ibovespa/CDI & & Mean & Std. & q2.5\% & Median & q97.5\% \\
\hline Full sample & $\kappa$ & 0.6401 & 0.8437 & 0.2065 & 0.6593 & 0.9714 \\
& $\theta$ & 0.0132 & 0.1731 & 0.0039 & 0.0143 & 0.0173 \\
& $\epsilon$ & 9.5988 & 1.4439 & 6.943 & 9.5155 & 12.5866 \\
First subsample & $\rho$ & -0.2913 & 0.1731 & -0.5651 & -0.3199 & 0.0871 \\
& $\mathrm{p}$ & 0.9163 & 0.0362 & 0.8437 & 0.9171 & 0.9842 \\
& $\kappa$ & 0.6158 & 0.2053 & 0.1743 & 0.6288 & 0.9652 \\
& $\theta$ & 0.0101 & 0.0043 & 0.0013 & 0.0104 & 0.0176 \\
Second subsample & $\epsilon$ & 7.2768 & 1.3317 & 4.8597 & 7.2376 & 10.098 \\
& $\rho$ & -0.0279 & 0.1141 & -0.2917 & -0.0109 & 0.1764 \\
& $\mathrm{p}$ & 0.9402 & 0.0407 & 0.8585 & 0.9408 & 1.0202 \\
& $\theta$ & 0.5308 & 0.2249 & 0.0916 & 0.5349 & 0.9435 \\
& $\epsilon$ & 0.0138 & 0.0069 & 0.0009 & 0.0147 & 0.0259 \\
& $\rho$ & 10.2321 & 1.4902 & 7.5616 & 10.1645 & 13.3897 \\
& $\mathrm{p}$ & 0.8851 & 0.0361 & 0.8134 & 0.8858 & 0.9529 \\
\hline
\end{tabular}

credibility interval estimates of parameter $p$ are uniformly above 0.8 and below 1.05 for all assets in the sample. Without inferring too much, this seems some indication that the range between 0.8 and 1.0 has some support from data, specially when compared to the calibrated value 0.5 of popular Heston-type models. Estimates of the correlation parameter $\rho$ for Oil and S\&P500 returns yield very disperse posteriors, negative mean and median. Here, again, Gold prices seem to display some difference in dynamics. Although the $95 \%$ credibility interval contains zero, much more probability is attributed to a positive correlation between returns and volatility shocks than for the other assets.

\section{Conclusion}

There is a compelling boom-bust narrative for Brazilian stock markets between January 2016 and March 2020, with extraordinary gains fueled by a steadily decreasing interest rate level and optimistic expectatives for output growth, which were then erased during the March 2020 COVID-19 crisis.

In this paper, we explored this narrative through the strict local martingale theory of financial bubbles. A certain financial asset has a bubble if is discounted price is not a "true" martingale under the equivalent risk-neutral probability measure, but a strict local martingale-whose expected value decreases with time. This study thus contributes with some statistical evidence to an ongoing debate regarding the past or current existence of bubbles in Brazilian stock markets, which is of relevance to both practitioners and researchers.

From the condition in Eq. (4), we have that an asset price follows a strict local martingale if its volatility increases with level faster than linearly. We employed 
Table 7 Posterior distributions, stochastic volatility modelS\&P500, oil, and gold

\begin{tabular}{lllllll}
\hline Asset & & Mean & Std. & q2.5\% & Median & q97.5\% \\
\hline S\&P500 & $\kappa$ & 0.6344 & 0.2457 & 0.1072 & 0.6692 & 0.9834 \\
& $\theta$ & 0.0068 & 0.0045 & 0.0001 & 0.0085 & 0.0133 \\
& $\epsilon$ & 11.6567 & 1.5544 & 8.7294 & 11.6059 & 14.7842 \\
& $\rho$ & -0.1560 & 0.2361 & -0.4633 & -0.2454 & 0.2616 \\
& $\mathrm{p}$ & 0.8107 & 0.0301 & 0.7485 & 0.8113 & 0.8663 \\
Oil & $\kappa$ & 0.6933 & 0.1813 & 0.2867 & 0.7108 & 0.9777 \\
& $\theta$ & 0.0062 & 0.0061 & 0.0003 & 0.0054 & 0.0162 \\
& $\epsilon$ & 9.8797 & 1.3836 & 7.2797 & 9.8369 & 12.8306 \\
& $\rho$ & 0.0401 & 0.0703 & -0.1374 & 0.0457 & 0.1650 \\
& $\mathrm{p}$ & 0.9252 & 0.0358 & 0.8539 & 0.9257 & 0.9958 \\
Gold & $\kappa$ & 0.7042 & 0.1807 & 0.3067 & 0.7239 & 0.9784 \\
& $\theta$ & 0.0044 & 0.0026 & 0.0002 & 0.0042 & 0.0092 \\
& $\epsilon$ & 8.0977 & 1.4080 & 5.6016 & 8.0369 & 11.0447 \\
& $\rho$ & 0.0327 & 0.0644 & -0.0657 & 0.0202 & 0.1950 \\
& $\mathrm{p}$ & 0.9298 & 0.0378 & 0.8542 & 0.9304 & 1.0001 \\
\hline
\end{tabular}

a nonparametric estimator for the diffusion coefficient based on Florens-Zmirou (1993), from those estimates of $\sigma^{2}\left(S_{t}\right)$ we have no indication condition (4) is satisfied, and thus no indication a SLM bubble is present in Ibovespa prices through the analyzed periods.

Then, we estimated a stochastic volatility model based on Andersen and Piterbarg (2007), whose parameter value configuration might indicate SLM behavior according to Theorem 1. A necessary condition for such is a positive correlation between innovations to returns and volatility, a feature which seems no be present in data.

For the sake of some comparison context, we also conducted exercises on three assets of great global importance: the S\&P500 index, spot oil prices, and spot gold prices. Results for S\&P500 and oil prices are qualitatively similar to those obtained for the Ibovespa index. Specifically, nonparametric estimatives of their variance functions do not increase faster than linearly as price grows, as required by the SLM condition in Eq. (4); furthermore, in our estimations of the stochastic volatility model (5), there is no evidence of a positive correlation coefficient between random shocks to returns and volatility. Gold prices seem to be an exception. Interestingly, gold prices dynamics seem different from what was observed for the other assets. Nonparametric estimation of its variance function suggests a sharp increase for higher observed prices and convergence of the integral in Eq. (4), characteristic of a strict local martingale process. Also, parametric estimation of the stochastic volatility model (5) attributes high probability to a positive correlation between shocks to Gold returns and unobserved volatility, thus characterizing the underlying price process as a strict local martingale according to the criteria in Theorem 1.

Thus, we take the results presented here as indication that the high returns experienced by Brazilian stocks from 2016 onward and the sudden drop in prices in March 2020, are not the case of a bubble forming up and then bursting-but better explained by market fundamentals and international spillovers. Qualitatively similar 
dynamics are observed for Ibovespa, S\&P500, and oil; namely, the absence of a positive price-variance feedback relationship, that is characteristic of strict local martingale bubbles, which reinforces the notion of those assets having typical behavior during the analyzed period.

Funding Authors acknowledge funding from CNPq (303738/2015-4) and FAPESP (2018/04654-9).

Data availability The data employed in this study is public and sources are described in the Appendix.

Code availability Replication codes are available upon request.

\section{Compliance with ethical standards}

Conflict of interest The authors declare that they have no conflict of interest.

\section{References}

Andersen LB, Piterbarg VV (2007) Moment explosions in stochastic volatility models. Finance Stoch 11(1):29-50

Bai J, Perron P (1998) Estimating and testing linear models with multiple structural changes. Econometrica $66(11): 47-78$

Bai J, Perron P (2003) Computation and analysis of multiple structural change models. J Appl Econ 18(1):1-22

Baldeaux J, Ignatieva K, Platen E (2018) Detecting money market bubbles. J Bank Finance 87:369-379

Camerer C (1989) Bubbles and fads in asset prices. J Econ Surv 3(1):3-41

Camerer C, Weigelt K (1991) Information mirages in experimental asset markets. J Bus 64(4):463-493

Chaim P, Laurini MP (2019) Is bitcoin a bubble? Phys A Stat Mech Appl 517:222-232

Cretarola A, Figà-Talamanca G (2019) Detecting bubbles in Bitcoin price dynamics via market exuberance. Ann Oper Res. https://doi.org/10.1007/s10479-019-03321-z

Delbaen F, Schachermayer W (1998) The fundamental theorem of asset pricing for unbounded stochastic processes. Math Ann 312(2):215-250

Diebold FX, Yilmaz K (2009) Measuring financial asset return and volatility spillovers, with application to global equity markets. Econ J 119(534):158-171

Duane S, Kennedy AD, Pendleton BJ, Roweth D (1987) Hybrid Monte Carlo. Phys Lett B 195(2):216-222

Flood RP, Hodrick RJ (1986) Asset price volatility, bubbles, and process switching. J Finance 41(4):831-842

Florens-Zmirou D (1993) On estimating the diffusion coefficient from discrete observations. J Appl Probab 30(4):790-804

Greenwald BC, Stein JC (1991) Transactional risk, market crashes, and the role of circuit breakers. J Bus 84(4):443-462

Hurvich CM, Simonoff JS, Tsai CL (1998) Smoothing parameter selection in nonparametric regression using an improved akaike information criterion. J R Stat Soc Ser B Stat Methodol 60(2):271-293

Jarrow RA, Protter P, Shimbo K (2010) Asset price bubbles in incomplete markets. Math Finance 20(2):145-185

Jarrow R, Kchia Y, Protter P (2011) How to detect an asset bubble. SIAM J Financ Math 2(1):839-865

Jarrow R, Protter P, Shimbo K (2007) In: Fu MC, Jarrow RA, J YJ, RJ E (eds) Advances in mathematical finance. Applied and Numerical Harmonic Analysis, Birkhauser Boston, chap asset price bubbles in complete markets

Jiang GJ, Knight JL (1997) A nonparametric approach to the estimation of diffusion processes, with an application to a short-term interest rate model. Econ Theory 13(5):615-645

Kodres LE, O'Brien DP (1994) The existence of pareto-superior price limits. Am Econ Rev 84(4):919-932 
Kotani S (2006) On a condition that one-dimensional diffusion processes are martingales. In Memoriam Paul-André Meyer. Springer, Berlin, pp 149-156

Kuhn B, Kuserk G, Locke P (1991) Do circuit breakers moderate volatility? Evidence from October 1989. Rev Futures Mark 10(1):136-174

Martins C (2020) Bolha ou alta consistente: o que está acontecendo na bolsa de valores? Gazeta do Povo. https://www.gazetadopovo.com.br/economia/bolha-ou-alta-consistente-o-que-esta-acontecendo-nabolsa-de- valores/. Accessed 2 Sept 2020

Mijatović A, Urusov M (2012) On the martingale property of certain local martingales. Probab Theory Relat Fields 152(1-2):1-30

Nunes MS, Silva SD (2009) Bolhas racionais no índice bovespa. Revista Brasileira de Economia 63(2):119-134

Obayashi Y, Protter P, Yang S (2017) The lifetime of a financial bubble. Math Financial Econ 11(1):45-62

Protter P (2013) A mathematical theory of financial bubbles. In: Paris-Princeton lectures on mathematical finance 2013, Springer, pp 1-108

Santoni GJ, Liu T (1993) Circuit breakers and stock market volatility. J Futures Mark 13(3):261-277

Smith VL, Suchanek GL, Williams AW (1988) Bubbles, crashes, and endogenous expectations in experimental spot asset markets. Econometrica 56(5):1119-1151

Stan Development Team (2020) RStan: the R interface to Stan. R package version 2.19.3. http://mc-stan. org/. Accessed 1 May 2020

Zeileis A, Kleiber C, Krämer W, Hornik K (2003) Testing and dating of structural changes in practice. Comput Stat Data Anal 44(1-2):109-123 